\title{
E-Service Requirements from a Consumer-Process Perspective
}

\author{
Martin Henkel and Erik Perjons \\ Department of Computer and Systems Sciences, Stockholm University \\ Forum 100, SE-16440, Kista, Sweden \\ \{martinh, perjons\}@dsv.su.se
}

\begin{abstract}
Context and motivation] When designing e-services it is important that they fit smoothly into the service consumers' business processes. If the e-services do not fit there is a risk that they will not be used by the consumers; the investment and effort to use the e-services might be too high. [Question/problem] In this paper, we aim at describing an approach for analysing requirements on e-services from the service consumers' perspective. [Principal ideas/result] The approach supports the identification and analysis of problems that e-services can cause in consumers' business processes. The presented approach is also supporting identification of tentative solutions such as changes in the e-services, business processes, IT systems or legal regulations. [Contribution] The approach contributes to the area of e-service requirements analysis by taking a consumer and process centric perspective. The approach is grounded in and illustrated by a case at the Swedish Tax Agency.
\end{abstract}

Keywords: process analysis, e-service requirements, e-service design.

\section{Introduction}

Generally, e-services can be used in a wide range of situations. For example, e-services can be used for information exchange; for ordering of products; or for more elaborative business collaborations. Central to service usage can arguably be the interaction between the service provider and the service consumer (sometimes called the "service user"). In order for the service consumer to use an e-service, the service needs to be valuable for the consumer [1]. However, the consumer value of the service can be hampered if the consumer needs a large investment or effort in order to use the service. In a commercial setting this can mean that the consumer may not use the service for requesting information or for ordering of products. Likewise, for an e-service provided by the government, such as online tax declaration/tax return, this can mean that the consumer will not use the e-service. Instead, the consumer will send in the tax declaration using paper forms and traditional channels, which will increase the administrative costs for the tax agency.

The adjustment effort, or investment, that is needed for a consumer to use an e-service can be particularly unfortunate for the use of governmental e-services. The reason behind this is that some governmental e-services at a first glance give little immediate consumer value. For example, companies that are submitting tax 
declarations do not get any immediate value in return. (Of course, companies do get something in return, in the form of public roads etc [2].) Thus, the effort of using this kind of governmental e-services needs to be low in order for consumers to start using them. This is especially true if there are alternative ways of achieving the same result. For example, many companies have developed a business process for manually managing tax declarations using paper forms and traditional channels. Using the e-service instead may cause changes in the company's business processes as well as supporting IT systems, which, in turn, may require extra investments and/or efforts. These changes in the process can be at best annoying for the company, or in the worst case require substantial investments to be dealt with.

The problem addressed in this paper is that e-services can cause problems in consumer processes. That is, requirement elicitation activities for designing e-services need to broaden their scope and also consider the e-services' impact on the consumers' business processes.

The goal of the paper is to present an approach for identifying and analysing problems related to the e-services impact on the consumers' business processes. The approach also supports identification of tentative solutions. These solutions consist of a combination of changes on the service provider's and/or the service consumers' sides. More precisely, the suggested solutions consist of improvements in the consumers' business processes enabled by changes in the provider's e-services; the provider's business and legal regulations; or the consumers' IT systems.

The approach is grounded in and illustrated by a case study performed at the Swedish Tax Agency. The work is a part of a research project, named SAMMET [3]. One of the problems investigated in the project was that an e-service developed by the Swedish Tax Agency was not used as much as expected. The e-service was aiming at supporting companies to send in tax declarations to the Swedish Tax Agency electronically. However, a large group of companies were continuing to use paper forms and traditional channels instead of using the e-service. In order to analyse the limited use of the e-service, we investigated the e-service design as well as the IT and business context on both the service provider's and service consumers' sides. We then designed and applied the approach presented in this paper.

The approach is theoretically grounded in a four-aspect process framework [4] [5]. The process framework enables a structured approach to the process analysis and to structure the outcome of the approach. To aid the identification of possible solutions we furthermore apply a set of solution areas, based on that changes can be made to both IT and business on the consumers' and provider' sides of an e-service.

The remainder of this paper is structured as follows. In the next section, we describe research related to the approach. In Section 3, we give a short overview of the approach. In section 4-6, we describe the approach in detail. We also illustrate the approach using the Swedish Tax Agency case. Section 7 concludes the paper.

\section{Related Research}

Identifying, designing and implementing e-services introduce new challenges for business and IT architects. Compared to traditional information systems, service based systems are typically distributed among organisations. This means when designing and analysing e-services there is a need to consider a wider scope of 
requirements stemming from both the service provider and the service consumers. These issues have been addressed in the new subarea of requirements engineering that investigate service analysis and design. In this section, we describe how the approach presented in this paper relates to other research on e-services.

The relation between e-services and processes is discussed frequently in the literature. Particularly, the use of e-services is seen as a vehicle for process improvements. This view is predominant in the realm of Service Oriented Architectures, SOA. Several authors argue that e-services, and SOA, will be a base for building new, improved business processes [6][7]. In this paper, we take a different view: the view that a service can adversely affect the process it is used in. As a result, the findings can be used for e-service improvements as well as business process improvements.

There exist several methods on how to gather requirements for, and design e-services. Closest to the approach presented here are methods [8] [9] [10] that employ process models to design e-services. However these methods focus on the use of processes to create new e-services. In comparison to these methods, we use processes as a mean to analyse existing e-service designs, and to provide solutions for a better fit of the e-services in the service consumers' processes. Furthermore, the mentioned process based approaches focus on the activities and their relation in the processes for analysis, while we here apply a more elaborate four-aspect process framework. This enables us to perform a more detailed process analysis.

The view that information systems need to be analysed and evaluated in their context is argued for by several authors. For example, Scriven [11] argues that effects of a program should be evaluated by the effects as perceived by its users, as this way of evaluating is likely to catch unintended side-effects. This is in contrast to evaluate a service against its set up goals or intended effects. To rather examine the unintended effects is in line with the approach presented in this paper, since we try to discover problems or unintended effects that the use of a service has on a process.

The importance of studying e-services in their context is also pointed out by Goldkuhl [12]. Goldkuhl points out that e-services can have positive as well as negative effects for both service consumers and providers. In this paper, we focus on negative effects on the consumer side. Furthermore, Goldkuhl presents a generic method of how a software system in general should be designed to fit a certain organizational context [12]. However, the generic method does not include any concrete guidelines for how the analysis should be carried out. The approach presented in this paper is a first step towards aiding business and e-service analysts and designers with concrete guidelines how to perform this kind of analysis.

There also exist methods that makes use of goal models, such as $i^{*}$, to design e-services [13][14][15]. We do not apply goal models in our analysis, this would be a possible extension to capture alignment problems between e-services and high-level organizational goals. However, one benefit with the approach is that the approach still could be used if no goals are identified at the consumers' side. Another benefit is that the approach is concrete and highly focused on the day-to-day activities in the consumers' processes.

It is interesting to note that technically oriented service design principles, such as loose coupling [7] and service composability [6], are expressing the desire to design e-services that are affecting its usage context as little as possible. The reason behind these technical design principles is to create services that are usable in different 
technical settings. These kinds of principles are seldom found in more user interface and user-interaction oriented literature. The driver behind the approach presented in this paper is similar to the technical design principles - to create services that do not impose restrictions in their context of use.

\section{Overview of the Approach}

The goal of the approach presented in this paper is to identify and analyse problems that e-services cause in consumers' business processes. More precisely, we will focus on negative unintended effects on the processes, that is, the limitations that the e-services impose on the consumer processes.

The approach consists of three steps: consumer process identification, consumer process analysis and solution summary. To perform each step we provide one instrument in each of the steps. For example, the consumer process identification is supported by the use of a set of guiding questions. The three step approach is presented in Figure 1. Inputs to the steps are shown as arrows to the left side of boxes and output is represented as arrows from the right side of the boxes. The instruments used are represented as arrows associated with the bottom side of the boxes.

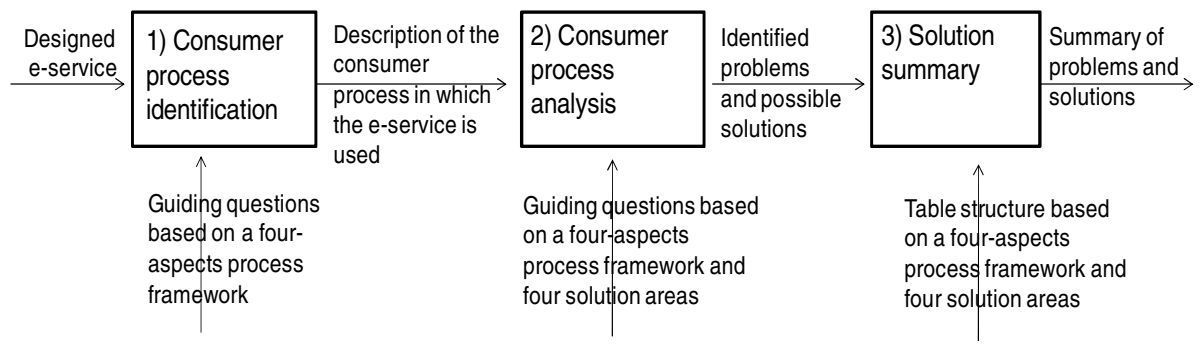

Fig. 1. Overview of the approach

Each of the three steps and used instruments are described in detail in Section 4, 5 and 6. These sections also show how the approach was applied in a case at the Swedish Tax Agency. The steps in the approach are briefly summarised below:

Step 1 - Consumer process identification. The aim of this step is the description of a consumer process in the form of its activities, the order of activities, the structure and content of information used and produced in the activities, as well as needed roles for service interaction. The step includes both the direct interaction required to use the eservice, and the wider context of the service use, i.e. the activities that precede and follows the service interaction. To guide the process identification, we provide an instrument in form of a set of guiding questions based on a four-aspect process framework.

Step 2 - Consumer process analysis. During this step the consumer process is examined to find problems caused by the e-service, as well as tentative solutions to these problems. To guide this step we propose an instrument in the form of another set of 
guiding questions. These questions are based on a combination of the aforementioned four aspect-process framework, and four solution areas. The four solution areas are: changes in the service consumers' business processes, changes in the e-service, changes in the provider's business rules (including legal regulations), and changes in the consumers' IT systems.

Step 3 - Solution summary. The problems and solutions found in the previous process analysis step are summarised according to the process aspects as well as the solution areas. To guide this summary, we provide an instrument in form of a simple table structure, describing problems and for each problem possible solutions. The table structure also shows how a solution in the form of a consumer process change must be supported by a change in at least one of the solutions areas: the service provider's business rules, the service provider's e-service or the service consumers' IT systems.

All three steps above could be performed by a process/e-service analyst in collaboration with the consumers of the e-service. In the case study presented in this paper, we used the guiding questions of step 1 and 2 in interviews with service consumers. However, the questions could also be used to guide workshops with several consumers present. The instrument in step 3 can be performed by a business analyst, in combinations with other approaches to estimate the cost of performing the changes, and to prioritize the changes.

\section{Process Identification}

In order to identify and describe the consumer process we need to examine not only the activities of the process that are directly interacting with the service, but also the activities that precede and follow the service interaction. We denote the activities that precede and follow the service interaction activities as the service context. Thus, in this step of the approach we will identify both activities within the service interaction and in the service context.

A process is not only about the activities and their relations. To analyse servicebased business process in depth, we also need to identify the process' use of information and role responsibilities. To cover all aspects of a process during the identification step, we rely on an existing four-aspect process framework [4][5]. According to this framework, a process can be described in four aspects:

- Functional - Describes the set of activities that are within the process

- Behavioral - Describes how the activities are interlinked, i.e. their order of execution and how the activities are synchronized in time.

- Informational - Describes the needed information that is used and produced by the activities within the process.

- Organizational - Describes who is responsible for executing the activities. This is commonly described by using roles.

The four aspects are interrelated. Thus, to describe a process in detail all four aspects need to be used. The four aspects should therefore not be seen as orthogonal. Instead, process analysts can use an aspect as a mean to intentionally focus on some characteristic of the process in detail, while putting other characteristics in the background. 
To cover all the above process aspects, and to cover both the service interaction and its context, we propose an instrument which consists of a set of simple guiding questions, see Table 1. The guiding questions are based on the four-aspect process framework described above. As shown in Table 1, we propose to have separate questions for the service interaction and the service context. This is to avoid a too narrow focus in the process analysis.

Table 1. Process identification questions, based on process aspects

\begin{tabular}{|l|l|l|}
\hline Process aspect & Within service interaction & In the service context \\
\hline Functional & $\begin{array}{l}\text { Which activities are needed within a } \\
\text { service interaction in order to use a } \\
\text { specific e-service? }\end{array}$ & $\begin{array}{l}\text { Which activities are needed for } \\
\text { preparation and handling of the result of } \\
\text { a service interaction for the e-service? }\end{array}$ \\
\hline Behavioural & $\begin{array}{l}\text { Which order of activities is needed } \\
\text { within a service interaction in order } \\
\text { to execute a specific e-service? What } \\
\text { requirements are put on the timing } \\
\text { and performance on these activities? }\end{array}$ & $\begin{array}{l}\text { Which order of internal activities is } \\
\text { needed in order to prepare for the } \\
\text { service interaction? How are the } \\
\text { activities that handle the result of the } \\
\text { interaction coordinated? }\end{array}$ \\
\hline Informational & $\begin{array}{l}\text { Which structure and content have the } \\
\text { information that is sent to external } \\
\text { parties during the service interaction? }\end{array}$ & $\begin{array}{l}\text { Which structure and content of the } \\
\text { internal information are needed for } \\
\text { preparation, and handling of the result, } \\
\text { of the use of the e-service? }\end{array}$ \\
\hline Organizational & $\begin{array}{l}\text { Which organizational role(s), or } \\
\text { individual(s) are needed to participate } \\
\text { in the service interaction in order to } \\
\text { execute a specific e-service? }\end{array}$ & $\begin{array}{l}\text { Which organizational role(s), or } \\
\text { individual(s) are needed for the } \\
\text { preparation before service interaction, } \\
\text { and for handling of the result of a } \\
\text { service interaction? }\end{array}$ \\
\hline
\end{tabular}

In order to identify and describe the consumers' tax declaration processes in the case study at the Swedish Tax Agency, we performed eleven semi-structured interviews with consumers of the tax agency's e-service. Out of the eleven interviews, six where performed with personnel at companies that worked as ombudsmen for tax declarations. These companies managed tax declarations of VAT and salaries for other companies. Thus, they had worked with the tax agency's e-service in different organisational settings. The other five interviews where performed with accountants working with the e-service at the company by which they are employed. Out of the eleven companies three had over 250 employees. During the interviews the guiding questions ensured that we identified information about the tax declaration processes with enough width and detail to get a good ground for further analysis.

The interviews led to a generalized graphical process model of the consumer's tax declaration process, and also textual descriptions. Figure 2 shows the resulting process diagram drawn by using the Business Process Model Notation (BPMN). The process is a simplification of both the service interaction and the service context that is performed at the companies. To simplify the process we only show the VAT process in Figure 2, and not the handling of the tax on salaries. Furthermore, we assume that all companies hand in declarations monthly. In reality smaller companies are 
allowed to do tax declarations quarterly or yearly. We have also removed some of the activities that some individual companies perform internally.

In the Tax Agency case there where substantial similarities in how the service consumers performed the tax declaration process, we therefore drew one generic process model. Other options would be to draw one process model per consumer, or one per consumer segment. The later, having a process model per consumer segment, can be beneficial when having a wide range of different consumers.

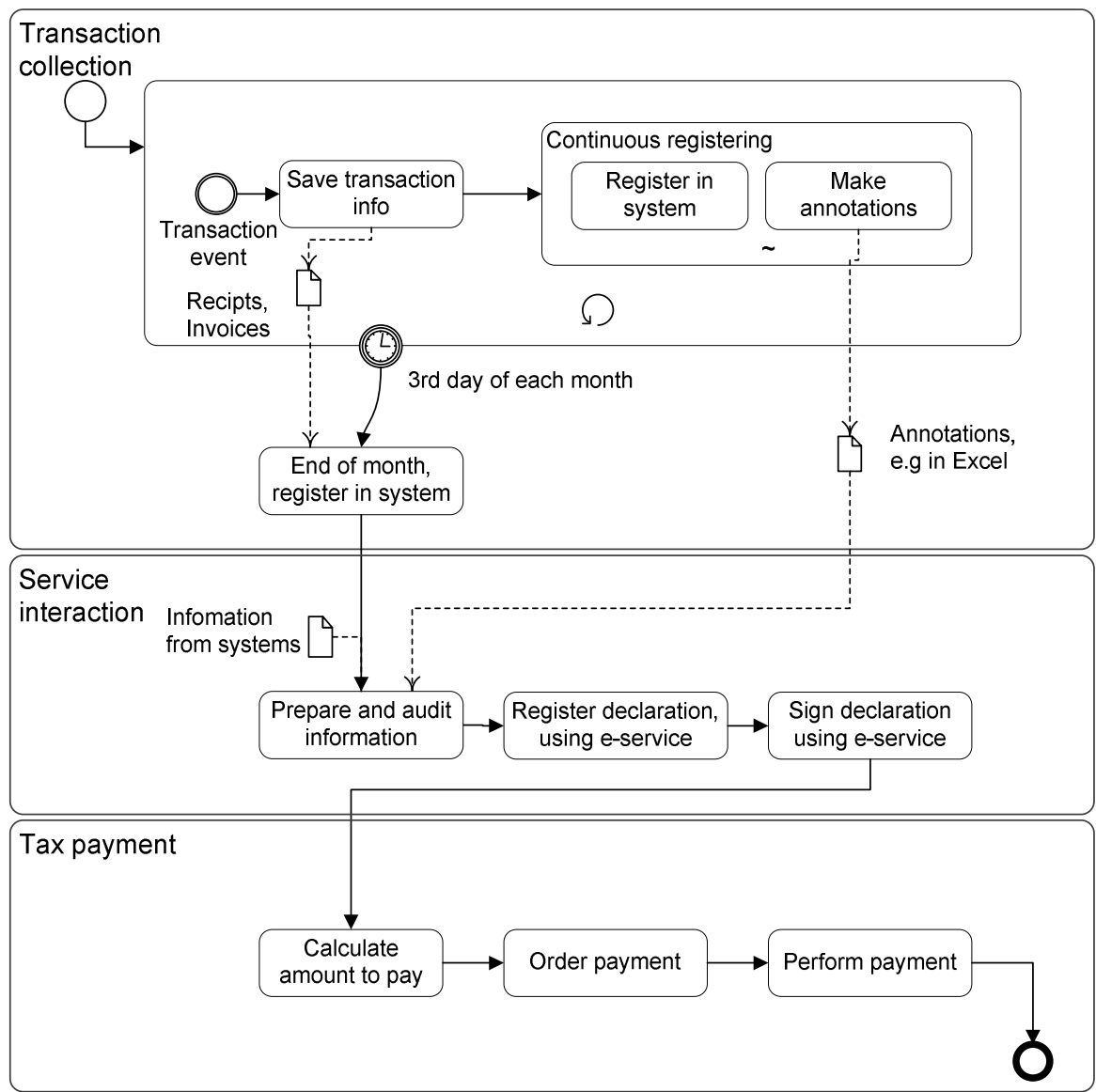

Fig. 2. The e-service consumer process

The tax declaration process (see Figure 2) starts with a transaction collection phase where the companies save receipts and invoices. Some of the companies perform continuous registration of the transactions in their systems. For special transactions, such as those that involve several countries, a special annotation is made, e.g. in an excel sheet or word document. All transactions need to be entered in the system on the 3rd day of each month at the latest. This phase is part of the service context. 
During the service interaction phase the information that has been collected is prepared and audited for the declaration, this includes considering the special annotations done previously. The information is then manually registered in the tax declaration e-service, and signed using a digital certificate.

During the tax payment phase the correct amount tax is paid by the companies by issuing a payment order. This phase is part of the service context.

Even though it is simplified, the textual process description above, and the model shown in figure 2, constitutes the result of the first step of the approach. The next step of the approach is to identify problems in the process.

\section{Process Analysis}

The four process aspects described earlier (functional, behavioural, informational and organisational) are excellent as a means to describe a process, but we cannot rely on it alone to identify problems in the process. The reason is that the four aspects only suggest certain areas of a business process to focus on when describing and analysing a business process. To identify the problems, the consumer process also needs to be related to optimal solutions that the current process diverts from. In a sense, a problem exists when there is a gap between a desired state of affairs and the actual. However, if no optimal solution is available, further means are needed, such as means for identifying the lack of resources in existing processes or finding alternative solutions to the existing one. Therefore, we propose four solution areas for solving problems in the consumer process.

The solution areas that we propose are based on the idea that solutions can exist in the form of business changes or IT changes. Furthermore, these business and/or IT changes can be implemented at the consumer's or provider's sides. This combination gives four solution areas, as shown in figure 3.

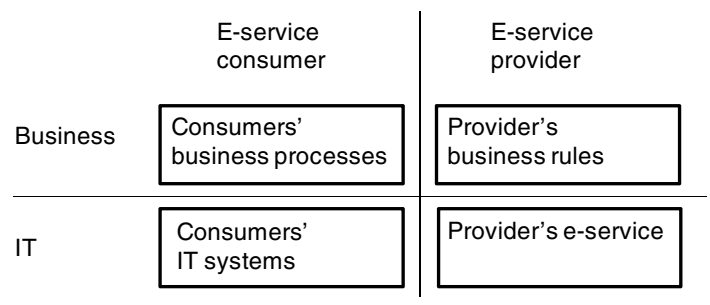

Fig. 3. The four pre-defined solution areas

The four solution areas are described below:

- Provider's e-service, i.e. the e-service designed and offered by the provider of the service (and used by the consumer).

- Provider's business rules, i.e. the business rules that govern the design and use of the e-service at the provider's side of the interaction. For example, when it comes to governmental e-services, this can be legal or organisational regulations. 
- Consumers' business process, i.e. the internal business process in which the eservice is used by the consumer of the service.

- Consumers' internal IT system, which supports the internal business process in which the e-service is used.

By combining the four aspects framework with the four solution areas, problems can be found as well as tentative solutions. Each problem will be associated with a certain process aspects, while solutions are related to solution areas. The solutions consist of a combination of changes on the service provider's and/or the service consumer's sides. More precisely, the suggested solutions consist of improvements in the consumer's business process enabled by changes in the provider's e-services; the provider's business rules; or the consumer's IT systems. For example, there might be activities in the consumers' business process that can be removed (problems in the functional aspect of the process) by an improved design of the providers business rules (a solution area).

To guide this step we propose an instrument in form of a set of guiding questions, based on this combination of the four aspect-process framework and the four solution areas. The guiding questions are presented in the next sub-sections, describing how the process can be analysed aspect by aspect.

\subsection{Analysing the Functional Process Aspect}

The functional aspect of a process concerns the activities carried out in a process, in our approach, the service consumer process. The activities can be a part of the service interaction, that is, they can be depending on interaction with the e-service. The activities can also be in the service context, that is, they can be performed before or after the service interaction.

E-Services that do not fit well with the consumer process will require additional activities compared to e-services that are designed with the consumer process in mind, or will include manual activities that could be automated. During the process analysis of the functional aspect we can thus examine if there are any unnecessary extra activities needed to use the service, and if there are unnecessary manual activities which could be automated. To guide the analysis of the functional aspect we can use two simple questions, based on the reasoning above:

- QF1 - Are there any extra activities in the process that can be avoided using an alternative design of the provider's e-service, provider's business rules, or consumers' internal IT systems?

- QF2 - Are there any manual activities in the process that can be automated using an alternative design of the provider's e-service, provider's business rules, or consumers' internal IT systems?

In the Tax Agency case (see Figure 2), we can firstly conclude (by using question $\mathrm{QF} 2$ ) that the submission of the tax declaration requires the companies (i.e. service consumers) to manually enter the figures into the Swedish Tax Agency's (i.e. service provider's) e-service (the Register declaration activity in Figure 2). This activity could have been automated if there was a possibility to interconnect the consumers' internal IT support with the Swedish Tax Agency's system. Thus, we conclude that 
there is an alternative design that concerns the consumers' internal IT systems, and the provider's e-service design.

We can also conclude (by applying question QF1) that there are activities that are used for overcoming limitations in the service consumers' IT systems, namely the "Make annotations". These annotation activities are performed because the current IT support does not fully support the Swedish VAT regulations. In this case, these annotation activities would not be necessary if the e-service and IT systems where designed to follow the same standard procedures and rules, and have open interfaces. This problem can be related to two solution areas, an alternative internal IT system design or an alternative design of the Swedish Tax Agency's business rules. Even if it is unlikely that the Swedish VAT rules will be changed to conform to system implementations at the service consumers' side, posing the questions reveals that there are discrepancies between the IT systems that the service consumers' use and the business rules at the service provider's side imposed via the service.

\subsection{Analysing the Behavioural Process Aspect}

The behavioural aspect of a process concerns the control flow, i.e. in which order the activities are arranged in relation to each other. The control flow is expressed using a set of basic control flow constructs: sequence, synchronizations and conditional branching.

Ideally the service would not affect a process' behavioural aspect. This means that the service should introduce as few sequences, synchronizations and conditional branches as possible. When analyzing how the service causes problems in a process we can thus look for process flow constructs that are unnecessary with alternative solutions. To aid in analyzing the process we have three basic questions, based on the three types of flow constructs:

- QB1 - Are there any unnecessary constraints put on the sequencing of activities in the process that can be avoided using an alternative design of the provider's e-service, provider's business rules, or consumers' internal IT systems?

- QB2 - Are there any extra complexity in the process due to conditional branching that could be avoided by an alternative design of the provider's e-service, provider's business rules, or consumers' internal IT systems?

- QB3 - Are there any unnecessary constraints put on the process hindered because of the need to perform synchronization of parallel flows that can be avoided using an alternative design of the provider's e-service, provider's business rules, or consumers' internal IT systems?

Looking at the Tax Agency case (see Figure 2), we can see that the behavioural aspect is quite simple - there are few uses of branching and parallel flows. The most complex part of the process is actually before the interaction with the service occurs, i.e. when the information to put into the tax declaration is collected in the "Save transaction" and "Register in system". We can conclude (with the aid of question QB1) that all "Save transaction" and "Register in system" activities must be performed before the service is used. This can be considered as a requirement put on the behavioural aspect of the process. Another design of the provider's e-service and business rules that 
allows continuous reporting of transactions would get rid of this dependency between activities.

Even if it is not shown in the example process, the use of the e-service also put requirements on the process synchronization. When a company declares in and outgoing VAT it also needs to declare the paid salaries for the same month. This means that two sub-processes, the salary process (not shown) and the VAT process (shown in Figure 2), need to converge/synchronize in a single activity, the "Register declaration" activity. This dependency can be found by using question QB3.The reason behind the need to declare both VAT and salaries at the same time can be traced back to the use of paper forms - it was considered simpler to just use a single paper form for both declarations. A simple solution can be found in the e-service solution area - just separate the handling of VAT and tax put on salaries.

\subsection{Analysing the Informational Process Aspect}

The informational aspect of a process concerns the information structures needed for performing its activities. The information structures include the information sent and received from the service under study, as well as information that are internal to the process, i.e. the information sent and received in the service context. Services that do not fit well with the process will require the information to be restructured, for example by requiring that the information is sent in several "documents" rather than one. To discover the services impact on the informational aspect we provide the following guiding question:

- QI1 - Are there any unnecessary re-packaging of information that can be avoided by using an alternative design of the provider's e-service, provider's business rules, or consumers' internal IT systems?

In the Tax Agency case (see Figure 2) we have already seen that the functional aspect of the process is affected because supporting IT systems are not following the same standard procedures and rules as the e-service designed by the Swedish Tax Agency. This mismatch also affects the informational aspect. Even thought detailed document flow is not provided in the sample process, we can see (using QI1) that the extra information provided during the "Make annotations" is required to be merged into the main declaration information in the activity, i.e. "Prepare and audit information". In essence this means that an information requirement is affecting not only the informational aspect, but also the functional, because there is a need to have extra activities to produce the requested information. As stated in Section 5.1, the alternative solution to this problem is potentially to change the provider's business rules or the consumers' IT systems.

\subsection{Analysing the Organisational Process Aspect}

The organisational aspect of a business process concerns who is responsible for executing the activities. In some process modelling notations, such as BPMN and UML Activity diagrams, swim lanes/partitions are used in the diagram to group together activities that a role is responsible for or should be performed by. Roles can be 
representing an entire organisation (i.e. "Manufacturer", "Service consumer"), or roles within an organisation (i.e. "Accountant", "CIO").

When analysing if an e-service causes problems in the process organisational aspect, we need to examine which roles are needed to perform the service interaction, and the activities that are executed before and after the interaction. To discover limitations to the use of roles and individuals we propose to use the following questions:

- QO1 - Are there any unnecessary use of specific roles that can be avoided by using an alternative design of the provider's e-service, provider's business rules, or consumers' internal IT systems?

- QO2 - Are there any unnecessary limitation of the number of actors/individuals that can take different roles and that can be avoided by using an alternative design of the provider's e-service, provider's business rules, or consumers' internal IT systems?

The organisational aspect (in the form of swim lanes/partitions) is not shown in the process of the Tax Agency case (Figure 2) to avoid cluttering. The use of the declaration e-service does not impose any restrictions on who performs each activity - except when it comes to the signing of the declaration. This can only be done by someone who is authorized signatory of the company (typically the owners and CEO) or an appointed ombudsman for declarations. Thus, posing the QO1 question points us towards some restrictions in the service design. The solution, if needed, is to be found in the areas of changed provider's business rules. The rules could be changed so there is a possibility for more roles to sign the declaration than is allowed today according to rules at the Swedish Tax Agency.

It is interesting to note that the restrictions of requiring a traditional authorised signatory is somewhat amended by the possibility to appoint a specific individual as ombudsman. However, the use of ombudsman to perform the signature is quite limited - since there can only be a single individual appointed for each company (this limitation is exposed by asking the questions QO2). The Swedish Tax Agency is currently investigating the possibility of changing the regulations so that a company can have several ombudsmen that are allowed to sign the declarations. This change is clearly in the provider's business rules solution area.

\section{Solution Summary}

The result from the previous step is a number of problems that an e-service causes in a consumer's business process as well as potential solutions. Each problem is associated with a certain process aspects, and the solutions are related to solution areas as well. However, each problem can have several solutions, and each solution require a mix of changes in different solution areas. This will give a rather complex picture of problems and possible solutions. Thus, the identified problems and solutions need to be presented so that the managers and e-service designers can get an overview, and, thereby, make rational decisions which solution to choose to solve a certain problem. Therefore, in this step, we introduce an instrument in form of a simple table structure. 
Table 2. Overview of the problems and solutions

\begin{tabular}{|c|c|c|c|c|c|}
\hline Aspect & Problem & $\begin{array}{l}\text { Consumer } \\
\text { Process } \\
\text { Improvement }\end{array}$ & $\begin{array}{l}\text { Provider } \\
\text { Rules }\end{array}$ & $\begin{array}{l}\text { Provider } \\
\text { E-Service }\end{array}$ & $\begin{array}{l}\text { Consumer } \\
\text { IT systems }\end{array}$ \\
\hline \multirow{3}{*}{ 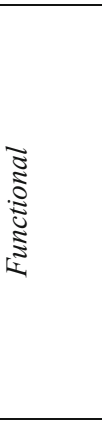 } & $\begin{array}{l}\text { Manual entry of } \\
\text { declarations }\end{array}$ & $\begin{array}{l}\text { Remove } \\
\text { activity, let the } \\
\text { system interact } \\
\text { with e-service } \\
\end{array}$ & & $\begin{array}{l}\text { New service } \\
\text { API needed }\end{array}$ & $x$ \\
\hline & $\begin{array}{l}\text { Unnecessary } \\
\text { annotations } \\
\text { activities }\end{array}$ & $\begin{array}{l}\text { Remove } \\
\text { activities, let the } \\
\text { IT system } \\
\text { handle this }\end{array}$ & $\begin{array}{l}\text { Change tax } \\
\text { rules to fit } \\
\text { systems }\end{array}$ & $\times$ & \\
\hline & $\begin{array}{l}\text { Unnecessary } \\
\text { annotations } \\
\text { activities }\end{array}$ & $\begin{array}{l}\text { Remove } \\
\text { activities, let the } \\
\text { IT system } \\
\text { handle this }\end{array}$ & & & $\begin{array}{l}\text { Change } \\
\text { systems to } \\
\text { fit rules }\end{array}$ \\
\hline \multirow{2}{*}{ 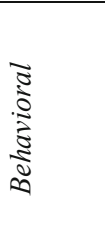 } & $\begin{array}{l}\text { Transactions } \\
\text { handled on a } \\
\text { monthly basis }\end{array}$ & $\begin{array}{l}\text { Remove the } \\
\text { monthly } \\
\text { collection of } \\
\text { transactions }\end{array}$ & $\begin{array}{l}\text { Allow } \\
\text { continuous } \\
\text { reporting }\end{array}$ & $x$ & $x$ \\
\hline & $\begin{array}{l}\text { Merged handling } \\
\text { of VAT and } \\
\text { salaries }\end{array}$ & $\begin{array}{l}\text { De-couple the } \\
\text { VAT and salary } \\
\text { declarations }\end{array}$ & & $\begin{array}{l}\text { Separate } \\
\text { VAT and } \\
\text { salary entry }\end{array}$ & \\
\hline 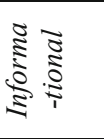 & $\begin{array}{l}\text { (same as } \\
\text { functional and } \\
\text { behavioral in the } \\
\text { case) }\end{array}$ & & & & \\
\hline \multirow{2}{*}{ 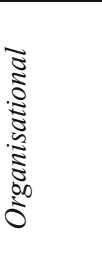 } & $\begin{array}{l}\text { Limited set of } \\
\text { roles allowed to } \\
\text { sign }\end{array}$ & $\begin{array}{l}\text { Let the signing } \\
\text { activity be } \\
\text { performed by } \\
\text { more roles }\end{array}$ & $\begin{array}{l}\text { Expand the } \\
\text { roles allowed } \\
\text { to sign }\end{array}$ & $x$ & \\
\hline & $\begin{array}{l}\text { Only one } \\
\text { individual can act } \\
\text { as ombudsman }\end{array}$ & $\begin{array}{l}\text { Let any } \\
\text { individual in a } \\
\text { role sign }\end{array}$ & $\begin{array}{l}\text { Allows } \\
\text { several } \\
\text { ombudsmen } \\
\text { to sign }\end{array}$ & $\times$ & \\
\hline
\end{tabular}

The table structure is as follows (see Table 2, in which we applied the table structure on the Tax Agency case): The two leftmost columns describe the process aspects and the identified problems. The following four columns show the solution areas. Each row represents a problem, and if a problem got several solutions it is simply repeated in several rows (see for example row 2 and 3). For every problem there is a consumer process solution that addresses the problem. However the consumer process change must be supported by a change in at least one of the solutions areas: the service provider's business rules, the service provider's e-service or the service consumers' IT systems.

A change in a solution area, which aims to enable a change in the consumers' business processes, can also cause changes in other solution areas. To indicate this in the table, we simply put a cross in the areas that can be caused. For example, a problem identified from the Tax Agency case is that transactions can only be handled on a 
monthly basis (see row four in Table 2). The problem can be solved by changing the consumers' processes so that they can manage such continuous reporting. This requires that the service provider's business rule change so that continuously reporting can be allowed at the Swedish Tax Agency. However, such a change of the provider's business rule can, in turn, cause changes in both the design of the e-service and the consumers' business processes and IT systems. Note that six out of seven proposed changes primarily affect the e-service provider. The changes in the consumer process are positive effects of these changes, i.e. they represent improvements from the consumer's perspective.

In the described Tax Agency case, the informational problems described in Section 5.3 overlap with the behavioural and functional problems described in Section 5.1. We therefore exclude the informational problems from the table.

The table can also be used as a basis for further detailing of the solutions. For example, there might be different cost associated to performing each solution.

\section{Conclusion}

In this paper, we have presented an approach for identifying and analysing problems related to the e-service impact on the consumers' business processes, as well as identifying tentative solutions. The approach is based on four well-known process aspects. Since the process aspects are well-known, the novelty of the approach lies elsewhere. Firstly, we consider a larger process scope than just the service interaction, that is, we advocate the analysis of its service context as well. Secondly, we use the four aspect framework to drive the analysis, but we provide a set of guiding questions, based on the framework, for simplifying the analysis. Furthermore, the usage of the questions ensures that no aspect of the process is overlooked. Thirdly, to aid both the problem and the solution identification we introduce a set of solution areas. The solution areas and process aspect are combined to get an overview of the identified problems and solutions. Again, in order to simplify this step, we provide a set of guiding questions to use. Finally, we present a table structure to visualise the complexity of problems and possible solutions and how a solution require of a mix of changes in different solution areas.

The presented approach leaves rooms for future research. The process perspective misses to describe things not related to activities and their inputs and outputs [16]. Thus, there is a need to combine the approach with other approaches to cover other effects of service use that cannot be described in the form of a process. Using goal models and value models could be candidates in this area [14]. Another limitation of the approach is that it cannot directly be applied to organisations that do not work according to a business process structure. For example, some work requires a more flexible ad-hoc working structure. Further work thus entails modifying the approach to cope with these circumstances. Finally, we would like to validate the approach in several case studies. Despite these areas for improvements we consider the approach to be a valuable part of any e-service designers' toolkit. 


\section{Acknowledgements}

The SAMMET project is partially funded by the Swedish agency for innovation systems (VINNOVA). The authors would like to thank the persons that participated in the interviews, as well as the personnel at the Swedish Tax Agency.

\section{References}

1. Edvardsson, B., Gustafsson, A., Johnson, M.D., Sandén, B.: New service development and innovation in the new economy. Studentlitteratur, Lund (2000)

2. Hruby, P., Kiehn, J., Scheller, C.: Model-Driven Design Using Business Patterns. Springer, Heidelberg (2006) ISBN 978-3540301547

3. SAMMET, SAMMET Project site (2010), http: / /www.dsv.su . se / sammet (accessed 2010-12-05)

4. Jablonski, S.: Workflow-Management-Systeme: Modellierung und Architektur. Thomson Publishing (1995)

5. Rausch-Scott, S.: TriGSflow - Workflow Management Based on Object-oriented Database Systems and Extended Transaction Mechanisms, PhD Thesis, University of Linz (1997)

6. Erl, T.: SOA Principles of Service Design. Prentice Hall, Englewood Cliffs (2007) ISBN 978-0132344821

7. Josuttis, M.: SOA in Practice: The Art of Distributed System Design. O'Reilly Media, Sebastopol (2007) ISBN 978-0596529550

8. Arsanjani, A., et al.: SOMA: A Method for Developing Service-Oriented Solutions. IBM Systsms Journal 47(3), 377-396 (2008)

9. Piccinelli, G., Emmerich, W., Zirpins, C., Schütt, K.: Web Service Interfaces for InterOrganisational Business Processes - An Infrastructure for Automated Reconciliation. In: Proceedings of the 6th International Enterprise Distributed Object Computing Conference (EDOC 2002), Lausanne, Switzerland, September 17-20, pp. 285-292. IEEE Computer Society Press, Los Alamitos (2002)

10. Papazoglou, M.P., Yang, J.: Design Methodology for Web Services and Business Processes. In: Buchmann, A., Casati, F., Fiege, L., Hsu, M.-C., Shan, M.-C. (eds.) TES 2002. LNCS, vol. 2444, pp. 54-64. Springer, Heidelberg (2002)

11. Scriven, M.: Evaluation Thesaurus. SAGE Publications, Thousand Oaks (1991) ISBN 9780803943643

12. Goldkuhl, G.: Socio-instrumental service modelling: An inquiry on e-services for tax declarations. In: Persson, A., Stirna, J. (eds.) PoEM 2009. LNBIP, vol. 39, pp. 207-221. Springer, Heidelberg (2009)

13. Gordijn, J., Yu, E., Raadt van der, B.: e-Service Design Using i* and e3 value Modeling. IEEE Software 23(3), 26-33 (2006)

14. Henkel, M., Johannesson, P., Perjons, E., Zdravkovic, J.: Value and Goal Driven Design of E-Services. In: The IEEE International Conference on e-Business Engineering (ICEBE 2007), Hong Kong, China, October 24-26 (2007)

15. Bleistein, S., Cox, K., Verner, J., Phalp, K.: Requirements engineering for e-business advantage. Requirements Engineering 11(1), 4-16 (2006)

16. Goldkuhl, G., Röstlinger, A.: The significance of work practice diagnosis: Socio-pragmatic ontology and epistemology of change analysis. In: Goldkuhl, G., Lind, M., Ågerfalk, P.J. (eds.) Proceedings of Action in Language, Organizations and Information Systems, pp. 27-50 (2003) 